\title{
Association between cigarette smoking and the vaginal microbiota: a pilot study
}

\author{
Rebecca M Brotman ${ }^{1,2^{*}}$, Xin He $\mathrm{He}^{3}$, Pawel Gajer ${ }^{1}$, Doug Fadrosh ${ }^{1}$, Eva Sharma ${ }^{4,5}$, Emmanuel F Mongodin ${ }^{1,6}$, \\ Jacques Ravel ${ }^{1,6}$, Elbert D Glover ${ }^{4}$ and Jessica M Rath ${ }^{4,7}$
}

\begin{abstract}
Background: Smoking has been identified in observational studies as a risk factor for bacterial vaginosis (BV), a condition defined in part by decimation of Lactobacillus spp. The anti-estrogenic effect of smoking and trace amounts of benzo[a]pyrene diol epoxide (BPDE) may predispose women to BV. BPDE increases bacteriophage induction in Lactobacillus spp. and is found in the vaginal secretions of smokers. We compared the vaginal microbiota between smokers and non-smokers and followed microbiota changes in a smoking cessation pilot study.

Methods: In 2010-2011, 20 smokers and 20 non-smokers were recruited to a cross-sectional study (Phase A) and 9 smokers were enrolled and followed for a 12-week smoking cessation program (Phase B). Phase B included weekly behavioral counseling and nicotine patches to encourage smoking cessation. In both phases, participants self-collected mid-vaginal swabs (daily, Phase B) and completed behavioral surveys. Vaginal bacterial composition was characterized by pyrosequencing of barcoded $16 \mathrm{~S}$ rRNA genes (V1-V3 regions). Vaginal smears were assigned Nugent Gram stain scores. Smoking status was evaluated (weekly, Phase B) using the semi-quantitative NicAlert ${ }^{\circledR}$ saliva cotinine test and carbon monoxide (CO) exhalation.
\end{abstract}

Results: In phase A, there was a significant trend for increasing saliva cotinine and $\mathrm{CO}$ exhalation with elevated Nugent scores ( $P$ value $<0.005$ ). Vaginal microbiota clustered into three community state types (CSTs); two dominated by Lactobacillus (L. iners, L. crispatus), and one lacking significant numbers of Lactobacillus spp. and characterized by anaerobes (termed CST-IV). Women who were observed in the low-Lactobacillus CST-IV state were 25-fold more likely to be smokers than those dominated by L. crispatus (aOR: 25.61, 95 \% Cl: 1.03-636.61). Four women completed Phase B. One of three who entered smoking cessation with high Nugent scores demonstrated a switch from CST-IV to a Liners-dominated profile with a concomitant drop in Nugent scores which coincided with completion of nicotine patches. The other two women fluctuated between CST-IV and L. iners-dominated CSTs. The fourth woman had low Nugent scores with L. crispatus-dominated CSTs throughout.

Conclusion: Smokers had a lower proportion of vaginal Lactobacillus spp. compared to non-smokers. Smoking cessation should be investigated as an adjunct to reducing recurrent BV. Larger studies are needed to confirm these findings.

Keywords: Vaginal microbiota, Smoking cessation, Cigarette, 16S rRNA gene analysis, Bacterial vaginosis

\footnotetext{
* Correspondence: rbrotman@som.umaryland.edu

${ }^{1}$ Institute for Genome Sciences, University of Maryland School of Medicine, Baltimore, MD, USA

${ }^{2}$ Department of Epidemiology and Public Health, University of Maryland

School of Medicine, 801 West Baltimore Street, Room Number 633,

Baltimore, MD 21201, USA

Full list of author information is available at the end of the article
} 


\section{Background}

Cigarette smoking is strongly associated, and often found in a dose-dependent relationship, with risk of bacterial vaginosis (BV) [1-12]. The relationship persists after controlling for other known confounders such as sexual behaviors and alcohol use [13]. BV is a common clinical syndrome in which the protective lactic acidproducing bacteria, mainly species of the Lactobacillus genus, are in low relative abundance and are supplanted by a diverse array of anaerobic bacteria [14]. BV sufferers frequently report morbidity, including vaginal odor and irritation, [15] emotional, sexual, and social impacts, [16] and are at higher risk for sexually transmitted infections upon exposure [17]. Conventional therapy consists of nitoimidazoles or clindamycin administered orally or topically [15]. Unfortunately, BV can be highly recurrent [18] with over $50 \%$ of women experiencing a symptomatic relapse within 3-12 months following antibiotic therapy [19]. An unexplored intervention for BV is smoking cessation.

Bagaitkar et al. cite three mechanisms by which tobacco affects bacterial infections across the human body: physiological and structural changes, increase in bacterial virulence, and dysregulation of immune function [20]. Nicotine and its metabolite cotinine have been detected in the cervical mucus of smokers [21-23]. It is also hypothesized that smoking leads to an accumulation of vaginal amines, [21] which combined with the antiestrogenic effect of smoking [24] predisposes a woman to BV. Women who smoke have significantly lower levels of mid-cycle and luteal phase estradiol compared with nonsmokers, [24] and it is well documented that the vaginal microenvironment is influenced by endogenous estrogen [25-27]. In addition, trace amounts of benzo[a]pyrene diol epoxide (BPDE) are found in the vaginal secretions of women who smoke and BPDE significantly increases bacteriophage induction in lactobacilli [28]. Smoking may then reduce the abundance of protective vaginal lactobacilli in part by promoting phage induction.

We hypothesize that the composition of vaginal bacterial communities (termed the vaginal microbiota) is strongly affected by smoking. In this study we compared the vaginal microbiota, as determined by $16 \mathrm{~S}$ rRNA gene sequencing, between smokers and non-smokers, and we also followed changes in the vaginal microbiota over time in a pilot study of smoking cessation.

\section{Methods}

This manuscript details two separate Phases in our smoking study. The first (Phase A) was a cross-sectional study in which smokers and non-smokers were compared at a single time point. The second (Phase B) was a longitudinal study in which a subgroup of smokers from Phase A were recruited to a smoking cessation pilot study.

\section{Phase A: cross-sectional study}

In 2010-2011, 20 smokers and 20 non-smokers were recruited to a cross-sectional study (single visit) at the Center for Health Behavior Research (CHBR) at the University of Maryland School of Public Health (UMSPH). Inclusion criteria were non-pregnant, non-lactating women, aged 18 to 45 years. Women had to be healthy as determined by medical history, with absence of acute or chronic illnesses, including serious psychiatric disorders or current depression. In addition, participants were excluded if they had used an antibiotic or antimycotic in the prior 30 days or reported a known history of other drug or alcohol dependence in the prior 12 months. Current smoking status was determined by self-report and confirmed by carbon monoxide $(\mathrm{CO})$ exhalation and saliva cotinine measures (described below). Non-smokers also denied smoking in the prior year. Participants completed questionnaires on demographics, nicotine withdrawal, smoking urges, smoking history and tobacco use behavior, depression, nicotine dependence, and reproductive health history.

In a private clinic room, participants self-collected two mid-vaginal swabs (Copan flocked nylon elution-swab and Starplex double headed rayon swab), measured their vaginal $\mathrm{pH}$ using the $\mathrm{VpH}$ glove (Inverness Medical) and prepared a vaginal smear on a slide for Nugent Gramstain analysis [29]. The Nugent score reflects the relative abundance of large Gram-positive rods (lactobacilli), Gram-negative and Gram-variable rods and cocci (i.e., G. vaginalis, Prevotella, Porphyromonas, and peptostreptococci), and curved Gram-negative rods (i.e., Mobiluncus). This technique allows assessment of relative numbers of bacteria, allowing for classification of bacterial load. It is based on a linear scale ranging from $0-10$. A score of $0-3$ is considered normal, $4-6$ is an intermediate state, and $7-10$ is indicative of BV.

Self-collection of mid-vaginal swabs for microbiota analysis has been validated in several studies comparing self-collected to clinician-collected samples [30-32]. We have also validated the use of a home freezer $\left(-20^{\circ} \mathrm{C}\right)$ in a vaginal microbiota study which compared cold chain protocols [33].

\section{Phase B: a pilot longitudinal study of smoking cessation}

Phase B participants $(n=9)$ were recruited using the same criteria as Phase A. Additional inclusion criteria for the Phase B smoking cessation trial were being a current smoker who smoked at least 10 cigarettes/day, no reported period of smoking abstinence greater than three months in the prior year, no history of hypersensitivity to nicotine or adhesives, and motivation to quit smoking. Participants completed questionnaires on demographics, nicotine withdrawal, smoking urges, smoking history and current behavior, depression, nicotine dependence, and reproductive health history at their baseline visit. 


\section{Daily procedures at the participant's home}

Each day for the 12-week study, participants self-collected two mid-vaginal swabs (Copan flocked nylon elutionswab and Starplex double headed rayon swab), measured their vaginal $\mathrm{pH}(\mathrm{VpH}$ glove, Inverness Medical) and prepared a vaginal smear on a slide for Nugent Gram stain analysis [29]. The two vaginal swabs were stored at the participants' home in the freezer and the smear was stored in a slide container at room temperature. Participants transported samples to the CHBR weekly in coolers with cold packs to maintain frozen samples. The participants also completed daily diaries which documented time-varying factors including sexual activities, menstrual cycle, feminine hygiene, smoking and nicotine patch use.

\section{Weekly procedures at the study site}

All participants received one-on-one behavioral counseling each week [34] that consisted of an initial 20-minute session focused on setting the target quit date and preparing to quit (baseline visit) and approximately 10minute weekly sessions thereafter, focused on quitting or preventing relapse. Participants were given a modified copy of the National Cancer Institute's booklet entitled "Clearing the Air", a take-home aid for individuals in smoking cessation programs [35].

During the first ten weeks of the study, participants were asked to use Nicoderm $\mathrm{CQ}^{\circ}$ patches daily as an aid to quitting smoking and were individually trained on proper patch application by the study staff. Participants stepped down the nicotine patch levels according to a known efficacious dosing schedule: a $21 \mathrm{mg}$ patch in weeks 1 to $6,14 \mathrm{mg}$ patch in weeks 7 to 8 , and $7 \mathrm{mg}$ patch in weeks 9 to 10 [36]. There was no prescribed patch use in weeks 11-12 which represented a two-week nicotine-free observation period. At each weekly visit, smoking status and patch use was verified using saliva cotinine and $\mathrm{CO}$ measurements.

All participants in Phase A and Phase B provided written informed consent. Ethical approval was obtained from the Institutional Review Boards of the University of Maryland Baltimore (UMB) and the UMSPH.

\section{Biomarkers of smoking}

Smoking status was evaluated using both the semiquantitative NicAlert ${ }^{\circ}$ saliva cotinine test and Bedfont Micro Smokerlyzer ${ }^{\circ}$ to measure CO exhalation [37-40]. Breath CO has a 5-6- hour half-life so it is accurate in detecting a 24-hour time frame [41]. The half-life for cotinine is approximately 20 hours and therefore can identify longer term abstinence [42]. The cotinine test can detect six levels of concentrations from 0 to $2000+\mathrm{ng} / \mathrm{ml}$. In this study, a $\mathrm{CO}$ of greater than 8 parts per million (ppm) and a cotinine measurement of greater than $200 \mathrm{ng} / \mathrm{ml}$ defined a smoker. When a participant has quit smoking and is actively using the nicotine patch, they are expected to have slightly elevated cotinine levels [43].

\section{Composition of vaginal bacterial communities}

DNA extraction from vaginal swabs, PCR amplification and 454 pyrosequencing of the V1-V3 hypervariable regions of the $16 \mathrm{~S}$ rRNA genes were performed as previously described [44] using primers $27 \mathrm{~F}^{*}$ [45] and 534R [46].

The QIIME split_libraries.py script (version 1.7.0) [44] was used to demultiplex and quality filter sequence reads that had a perfect match to the unique sample-specific barcode sequence by: 1) removing primer and barcode sequences; 2) truncating reads to the first ambiguous base; 3) truncating reads to the first base of a 25 bp sliding window where the average quality within the window dropped below Q25; and 4) including only reads with lengths between 300-600 bp. Quality filtered reads were dereplicated (99\% similarity) using the UCLUST software package [47] and potential chimeric sequences were removed using the UCHIME component of UCLUST [48] prior to taxonomic assignment. Genus level taxonomic assignments were performed by using the RDP Naïve Bayesian Classifier [49], and further species level assignments of Lactobacillus sp. were performed using higher order Markov Chain Lactobacillus species models using the software speciateIT (speciateIT.sourceforge.net) [44]. For each sample, vectors of phylotype proportions were clustered into community state types (CSTs) as previously described by Gajer et al. [50].

\section{Statistical analysis}

Fisher's exact test and logistic regression were used to determine the association between vaginal bacterial CST and smoking status. Factors collected from questionnaires that had been identified on the basis of previous literature and biologic plausibility were evaluated in analyses. To assess differences in the bacterial community structure between smokers and non-smokers, we also utilized the classification and regression tree (CART) analysis. Data were analyzed using STATA/SE 10.0 for Windows (Stata Corporation, College Station, Texas) and the CART was performed in R (R Foundation for Statistical Computing, Vienna, Austria).

\section{Results}

\section{Phase A: cross-sectional study}

Forty women were enrolled in the cross-sectional study with an average age of 29 years (SD: 9.03, range 19-45). Of the 20 smokers, 11 women (55\%) reported smoking 1-10 cigarettes per day in the prior 30 days while 9 women (45\%) reported 11-20 cigarettes per day. Cotinine and $\mathrm{CO}$ levels matched self-reported smoking status (Table 1). There were no differences in self-reported 
Table 1 Factors associated with smoking status in a cross-sectional study, College Park, MD, n = 40

\begin{tabular}{|c|c|c|c|c|c|}
\hline & \multicolumn{2}{|c|}{ Non-smokers* } & \multicolumn{2}{|c|}{ Smokers } & \multirow[t]{2}{*}{$P$ value ${ }^{* *}$} \\
\hline & $\mathrm{n}$ & $\%$ & $\mathrm{n}$ & $\%$ & \\
\hline Vaginal community state type $(\mathrm{CST})^{\S}$ & & & & & 0.04 \\
\hline CST I, L. crispatus-dominated & 13 & 65.0 & 6 & 30.0 & \\
\hline CST III, L. iners-dominated & 4 & 20.0 & 4 & 20.0 & \\
\hline CST IV, Lactobacillus-deficient & 3 & 15.0 & 10 & 50.0 & \\
\hline Nugent Gram stain score & & & & & 0.02 \\
\hline $0-3$ & 17 & 85.0 & 10 & 50.0 & \\
\hline $4-6$ & 2 & 10.0 & 2 & 10.0 & \\
\hline $7-10$ & 1 & 5.0 & 8 & 40.0 & \\
\hline Vaginal $\mathrm{pH}^{+}$ & & & & & 0.13 \\
\hline$<=4$ & 10 & 50.0 & 4 & 20.0 & \\
\hline $4.1-5.5$ & 1 & 5.0 & 2 & 10.0 & \\
\hline $4.6-5.0$ & 4 & 20.0 & 3 & 15.0 & \\
\hline$>=5.1$ & 5 & 25.0 & 11 & 55.0 & \\
\hline Age & & & & & $<0.01$ \\
\hline $18-28$ & 17 & 85.0 & 5 & 25.0 & \\
\hline $29-39$ & 1 & 5.0 & 7 & 35.0 & \\
\hline $40-45$ & 2 & 10.0 & 8 & 40.0 & \\
\hline Ethnicity & & & & & 0.16 \\
\hline African-American & 5 & 25.0 & 10 & 50.0 & \\
\hline Asian/Pacific islander & 3 & 15.0 & 1 & 5.0 & \\
\hline Hispanic & 3 & 15.0 & 0 & 0.0 & \\
\hline Multi-racial & 1 & 5.0 & 3 & 15.0 & \\
\hline White & 8 & 40.0 & 6 & 30.0 & \\
\hline Marital status & & & & & 0.09 \\
\hline Never married & 17 & 85.0 & 10 & 50.0 & \\
\hline Married & 2 & 10.0 & 4 & 20.0 & \\
\hline Separated, divorced, widowed & 1 & 5.0 & 5 & 25.0 & \\
\hline Other & 0 & 0.0 & 1 & 5.0 & \\
\hline Education, years & & & & & 0.06 \\
\hline 12 & 0 & 0.0 & 5 & 25.0 & \\
\hline $13-16$ & 18 & 90.0 & 13 & 65.0 & \\
\hline$>=17$ & 2 & 10.0 & 2 & 10.0 & \\
\hline \multicolumn{6}{|l|}{ Biomarkers of smoking } \\
\hline Cotinine, ng/ml & & & & & $<0.01$ \\
\hline $0-10$ & 1 & 5.0 & 0 & 0.0 & \\
\hline $11-30$ & 17 & 85.0 & 0 & 0.0 & \\
\hline $31-100$ & 2 & 10.0 & 0 & 0.0 & \\
\hline $101-200$ & - & - & - & - & \\
\hline $201-500$ & - & - & - & - & \\
\hline $501-1000$ & 0 & 0.0 & 2 & 10.0 & \\
\hline$>1000$ & 0 & 0.0 & 18 & 90.0 & \\
\hline
\end{tabular}


Table 1 Factors associated with smoking status in a cross-sectional study, College Park, MD, $\mathbf{n}=\mathbf{4 0}$ (Continued)

\begin{tabular}{lllll}
\hline Carbon monoxide exhalation, ppm & & & \\
$0-7$ & 20 & 100.0 & 0 & 0.0 \\
$8-10$ & 0 & 0.0 & 11 & 55.0 \\
$11+$ & 0 & 0.0 & 9 & 45.0
\end{tabular}

\section{Self-reported factors}

Number of cigarettes per day

None

$1-10$

$11-20$

Symptoms in 24 hours prior to visit

Odor

Irritation

Itching

Burning

Pain on urination

Discharge

Diagnoses in the prior 2 months

\section{None}

Bacterial vaginosis

Trichomonas vaginalis and Chlamydia trachomatis

Number of male sex partners in the prior 2 months

$$
0
$$$$
1
$$$$
2-3
$$

Number of female sex partners in the prior 2 months

$$
0
$$

Lifetime number of sex partners

$0-4$

5-7

$8+$

Hormonal contraception (HC)

Other, non-HC

Oral contraceptive pill

Injectable

Frequency of vaginal douching in prior 2 months

None

Every now and then

1-2 times per month

1 time per week

More than one time per week

Sexual activity in prior 24 hours

No vaginal intercourse

Vaginal intercourse without a condom

\section{0 \\ 55.0 \\ 45.0}

$<0.01$

$<0.01$

100.0

0.0

55.0

45.0

0.0

25.0

0.0

0.0

0.0

0.0

25.0

95.0

0.0

5.0

0.63

26.3

57.9

15.8

0.73

94.1

5.9

11.1

5.6

83.3

15

0.19

57.1

28.6

14.3

5.6

0.06

63.2

5.3

26.3

0.0

5.3

0.34
75.0

15.0
0.70$$
>0.99
$$

0.73

63

73


Table 1 Factors associated with smoking status in a cross-sectional study, College Park, MD, n = 40 (Continued)

\begin{tabular}{|c|c|c|c|c|c|}
\hline Vaginal intercourse with a condom & 2 & 10.0 & 4 & 20.0 & \\
\hline Menstrual hygiene in prior 24 hours & & & & & $>0.99$ \\
\hline Sanitary napkin, no tampon & 11 & 57.9 & 11 & 64.7 & \\
\hline Sanitary napkin only & 2 & 10.5 & 1 & 5.9 & \\
\hline Tampon only & 4 & 21.1 & 4 & 23.5 & \\
\hline Tampon and sanitary napkin & 2 & 10.5 & 1 & 5.9 & \\
\hline
\end{tabular}

${ }^{\S}$ CST defined by Ravel et al. ${ }^{44}$

*Non-smoker defined by self-report and $0-200 \mathrm{ng} / \mathrm{ml}$ on saliva cotinine test (NicAlert ${ }^{\oplus}$ ) and 0-7 ppm on carbon monoxide exhalation (ppm), Bedfont Micro Smokerlyzer ${ }^{\oplus}$.

**P- values determined by Fisher's exact test.

${ }^{\dagger}$ CarePlan ${ }^{\circledast} \mathrm{VpH}$ Test Glove.

vaginal symptoms between smokers and non-smokers. One smoker reported a diagnosis of $\mathrm{BV}$ in the two months prior to her visit. Compared to non-smokers, smokers tended to be older, report a greater number of lifetime sexual partners, and a greater frequency of vaginal douching.

Vaginal microbiota clustered into three community state types (CSTs) [44]; two dominated by Lactobacillus spp. (L. iners (termed CST III), L. crispatus (CST I)), and one lacking significant numbers of Lactobacillus spp. and characterized by anaerobic and strictly anaerobic bacteria (CST-IV) (Figure 1). In prior work we split CST IV into CST IV-A and IV-B, [50] however, all but two of the samples were assigned to CST IV-B, and therefore CST IV-A samples were combined to one CST IV group as in Ravel et al. [44].

CST was significantly associated with smoking status ( $P$ value $=0.04)$. Fifty percent of smokers versus $15 \%$ of non-smokers were classified to the low-Lactobacillus CST IV (Table 1). Similarly, fewer smokers had a L. crispatus-dominated CST I (30\% in smokers versus 65\% in non-smokers). Smokers tended to have higher Nugent Gram-stain scores $(P$ value $=0.02)$ and higher vaginal $\mathrm{pH}(P$ value $=0.13)$ indicative of BV diagnosis compared to non-smokers. Among women observed to have high cotinine concentration $(>1000 \mathrm{ng} / \mathrm{ml})$ and $\mathrm{CO}$ exhalation ( $>11 \mathrm{ppm}), 56 \%$ were categorized to the lowLactobacillus CST IV $(P$ value $<0.04)$. There were also statistically significant trends for both increasing cotinine concentration and $\mathrm{CO}$ exhalation with increasing Nugent score $(P$ value $=0.004$ and $P$ value $=0.005$, respectively). Smokers may also have had more sexual exposures with $83 \%$ of smokers versus $15 \%$ of nonsmokers reporting a history of eight or more sexual partners $(\mathrm{p}<0.01)$.

In multivariate modeling adjusting for confounders associated with both BV and smoking (vaginal douching and lifetime number of sex partners), women who were observed in the low-Lactobacillus CST IV were 25-fold more likely to be smokers than those dominated by the
L. crispatus-dominated CST I (adjusted odds ratio (aOR): 25.61, 95\% CI: 1.03-636.61); Table 2). Age was nonsignificant in the multivariable model although there were wide divergences in age between smokers and nonsmokers. Ninety percent of the non-smokers were age $18-28$ versus $75 \%$ of the smokers were age $29-45$. The model was unable to adjust for contraceptive type because eight of the 40 women declined response on the survey and therefore further limited the sample size of the multivariate model.

In the CART analysis, bacteria from the genera Peptostreptococcus and Veillonella were identified as the most important bacterial predictors for smoking status among the 133 bacteria observed.

\section{Phase B: a pilot longitudinal study of smoking cessation}

Of the nine women who enrolled in Phase B, four completed the 12-week study, three discontinued at 5-8 weeks, and two dropped out immediately. None of the women in Phase B reported a clinician's diagnosis of symptomatic BV or antibiotic use during the study. Cotinine and CO levels of enrolled women suggest they maintained nicotine patch use (high cotinine levels) and quit smoking or reduced smoking (low CO levels) (Figure 2). Even among those women who were lost to follow-up at weeks $5-8$, cotinine and CO levels suggest good compliance with smoking cessation (data not shown).

Of the four women who completed the 12-week study, three entered the study with high Nugent scores and vaginal microbiota belonging to the low-Lactobacillus CST IV (Figure 2). Of these three women, one woman (ID\#1) demonstrated a possible response to smoking cessation. At week 10, coinciding with completion of the nicotine patch and smoking cessation program, her CSTs switched from CST IV to CST III (a L. iners-dominated) and CST I (L. crispatus-dominated) with a concomitant drop in Nugent scores. She did not report a vaginitis diagnosis during the study or in the two months prior to study entry, nor any antibiotic use during the study or any change in behaviors which she documented on the 


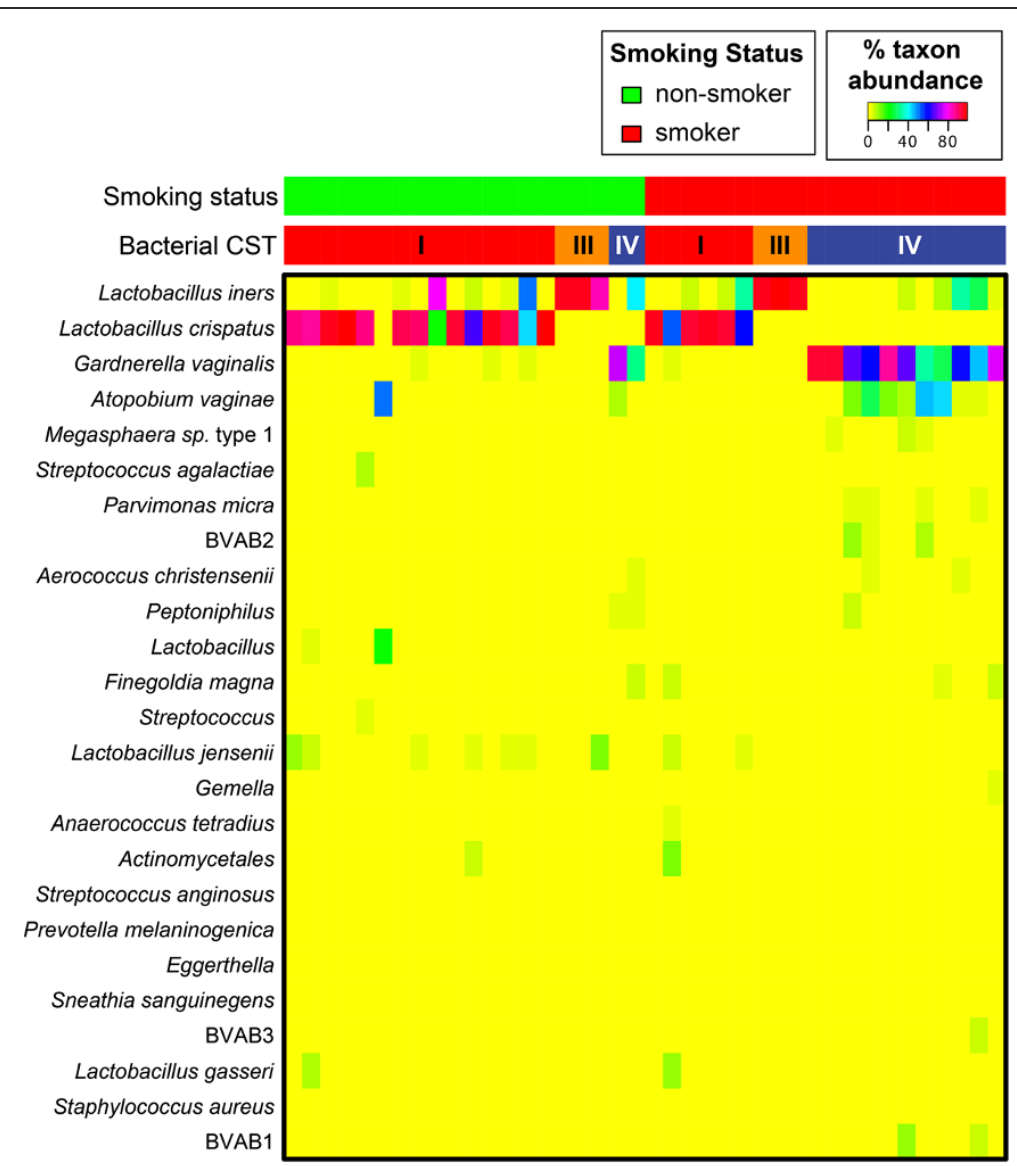

Figure 1 Heatmap of bacterial relative abundance from 20 smokers and 20 non-smokers sampled cross-sectionally. Each vertical line represents the bacterial composition of one participant. Smoking status is displayed at top in red and green. Bacterial community state type (CST) are determined vectors of phylotype proportions as previously described by Gajer et al. [50].

daily diaries. She reported intermittent vaginal odor and discharge on daily diaries but had no such complaints in the final two weeks of observation when she had ceased smoking, finished the nicotine patch protocol and switched to the Lactobacillus-dominated CSTs. The other 2 women (ID\#s 2 and 3) fluctuated between CST IV and CST III. The fourth woman (ID\#6) had low Nugent scores with L. crispatus-dominated CST I throughout (Figure 2). Among the three women that did not complete follow-up, Nugent scores fluctuated between low and intermediate categories. Longitudinal multivariate modeling was not possible in Phase B due to the small sample size $(n=4)$ of this pilot study, and therefore, we are limited to descriptive findings.

\section{Discussion}

The cross-sectional study (Phase A) suggests that women who smoke cigarettes are significantly more likely to have a vaginal microbiota characterized by low proportions of Lactobacillus spp. In Phase B, with one of three women shifting from a vaginal Lactobacillus-deficient CST to a Lactobacillus-dominated CST during smoking cessation without the aid of antibiotics, we hypothesize that smoking cessation could benefit some women struggling with recurrent BV. In order to establish the causal association that smoking directly affects the vaginal microbiome and recurrence of $\mathrm{BV}$, a larger smoking cessation study design is needed that also includes clinical evaluation for BV.

Several participants in Phase B fluctuated between a low-Lactobacillus state and a L. iners dominated CST with ID\#1 appearing to transition fully to a $L$. inersdominated CST. There has been recent species-specific attention to $L$. iners [51,52] L. iners is commonly found in the vagina [44] and has been associated with both BV and healthy states [53-56]. In addition, L. iners is often the first Lactobacillus species to recover after treatment for BV $[46,56]$. Our group's prior work suggest there are strains of $L$. iners which are highly stable over time while others are associated with a rapidly changing vaginal microbiota tending toward a BV state $[46,50]$. Ongoing work is evaluating the genomic heterogeneity of L. iners and if different strains are associated with STI or BV outcomes [57]. 
Table 2 Odds ratios for factors associated with smoking status, College Park, MD, $\mathbf{n}=\mathbf{4 0}$

\begin{tabular}{|c|c|c|c|c|c|c|c|c|}
\hline \multirow{2}{*}{ Community state type (CST), dominant bacteria } & \multirow[t]{2}{*}{ OR } & \multicolumn{2}{|c|}{$95 \% \mathrm{Cl}$} & \multirow[t]{2}{*}{$P$ value } & \multirow[t]{2}{*}{ Adjusted OR } & \multicolumn{2}{|c|}{$95 \% \mathrm{Cl}$} & \multirow[t]{2}{*}{$P$ value } \\
\hline & & & & & & & & \\
\hline CST-I, L. crispatus-dominated & REF & - & - & - & REF & - & - & - \\
\hline CST-III, L. iners-dominated & 2.17 & 0.40 & 11.74 & 0.37 & 2.66 & 0.19 & 38.04 & 0.47 \\
\hline CST-IV, Lactobacillus-deficient & 7.22 & 1.44 & 36.22 & 0.02 & 25.61 & 1.03 & 636.61 & 0.05 \\
\hline \multicolumn{9}{|l|}{ Age } \\
\hline $18-28$ & REF & - & - & - & & & & \\
\hline 29-39 & 23.80 & 2.34 & 242.29 & 0.01 & - & - & - & - \\
\hline $40-45$ & 13.60 & 2.15 & 85.86 & 0.01 & - & - & - & - \\
\hline Education, years & 0.82 & 0.61 & 1.10 & 0.18 & - & - & - & - \\
\hline Douching, past 2 months & 5.25 & 0.93 & 29.70 & 0.06 & 0.81 & 0.05 & 13.61 & 0.88 \\
\hline Currently menstruating & 1.00 & 0.29 & 3.45 & 1.00 & & & & \\
\hline \multicolumn{9}{|l|}{ Lifetime number of sex partners } \\
\hline $0-4$ & REF & - & - & - & & & & \\
\hline $5-7$ & 0.44 & 0.03 & 5.88 & 0.54 & 0.31 & 0.01 & 9.84 & 0.50 \\
\hline 8 or more & 20.00 & 2.75 & 145.48 & 0.00 & 40.70 & 2.46 & 674.00 & 0.01 \\
\hline \multicolumn{9}{|l|}{ Sexual activity in prior 24 hours } \\
\hline No vaginal intercourse & REF & - & - & - & - & - & - & - \\
\hline Vaginal intercourse with no condom & 3.00 & 0.61 & 14.86 & 0.18 & - & - & - & - \\
\hline Vaginal intercourse with a condom & 3.00 & 0.46 & 19.59 & 0.25 & - & - & - & - \\
\hline
\end{tabular}

${ }^{5}$ CST defined by Ravel et al. ${ }^{44}$

This pilot study provides important preliminary data for future studies. Attrition was high among participants attempting smoking cessation in Phase B (55\%), although those who remained in the study were very compliant with smoking cessation, nicotine patch use, attending weekly counseling sessions, and daily collection of vaginal swabs, vaginal $\mathrm{pH}$, vaginal smears and diary entries. Women who were lost to follow-up were also compliant with smoking cessation as indicated by biomarkers. Loss to follow-up rates greater than 30\% are not unusual in smoking cessation trials [58-61], and therefore a future study may need to recruit two-fold more women as our study indicates. Weekly visits confirmed that samples were collected in the week stipulated. We advocate that future studies include frequent self-collection of vaginal swabs (daily or 2-3 times weekly) with careful collection of the menstrual cycle, antibiotic use and behavioral data $[50,62,63]$. In addition, longer duration of follow-up ( $>12$ weeks) is likely necessary to capture all women if their microbiome is to rebound to Lactobacillus-dominated CSTs.

There are a number of limitations to this study. The research was designed as a pilot, and therefore, sample size and funds were limited. We were unable to conduct broad testing for sexually transmitted infections, and larger studies may be able to detect other known CSTs, such as CSTs dominated by $L$. gasseri and $L$. jensenii. It should also be noted that there are known racial and ethnic differences in nicotine metabolism, which may affect biomarkers of smoking exposure [64-66]. Cotinine and carbon monoxide levels matched self-report of smoking in our study. Also due to sample size, we were unable to control for important confounders. For example, another important factor which may be driving the inverse association between Lactobacillus-dominated CSTs (and also Nugent scores) with smoking status is hormonal contraception (HC). Use of $\mathrm{HC}$ in most epidemiological studies has been associated with a reduced risk of bacterial vaginosis [67]. Sixty percent of non-smokers versus $25 \%$ of smokers were using $\mathrm{HC}$. The differences in HC use likely reflects clinicians' prescribing patterns in which smokers are not prescribed $\mathrm{HC}$ due to potential cardiovascular side effects [68]. Further, smokers tended to be older (over age 40 and possibly peri-menopausal) and therefore less likely to use HCs. It was not possible for this analysis to use $\mathrm{HC}$ in statistical modeling because eight of the 40 women in Phase A declined to answer the contraceptive questions and the sample size became prohibitive. In addition, $\mathrm{HC}$ use was not different between smokers and non-smokers in univariate analysis $(P$ value $=0.19$ ). It remains important for future studies to collect $\mathrm{HC}$ formulation data and control for it in analysis.

It was also surprising to observe $5 \%$ of the nonsmokers versus $40 \%$ of smokers had high Gram stain 


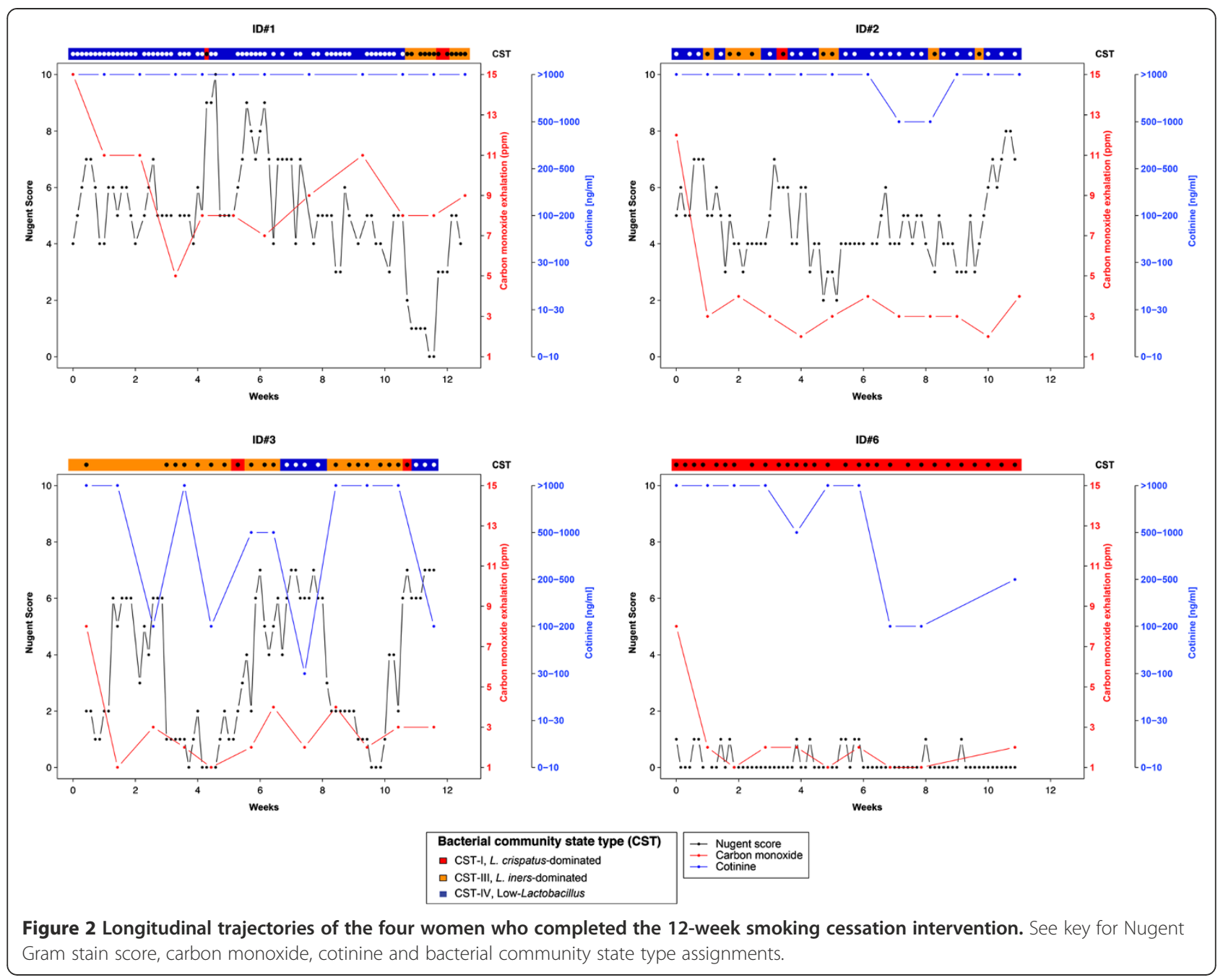

scores indicative of BV. This could have been the result of recruitment of "healthier" women than an average non-smoking cohort, and therefore, the non-smoking group was biased by women with Lactobacillus-dominated microbiota. However, non-smokers and smokers were recruited using the same methods of advertising and outreach, and more importantly, our data demonstrated that there were statistically significant doseresponses for increasing cotinine concentration and $\mathrm{CO}$ exhalation with increasing Nugent score. Numerous studies indicate BV is more common in smokers than nonsmokers, smoking has a dose-dependent relationship with $\mathrm{BV}$ and the associations persist after controlling for confounders [1-12]. The current study also utilized saliva cotinine and carbon monoxide exhalation measures (which prior studies have not collected) coupled with extensive surveys to properly categorize women as smokers and non-smokers. A larger study with more representative sampling, coupled with biomarker detection of smoking, could resolve this issue.
A major strength of this study is that we are able to provide preliminary data for future studies and self-report of smoking status was confirmed by biomarkers. The study also utilized comprehensive questionnaires, weekly counseling in smoking cessation and high-throughput DNA sequencing technologies. Participants self-collected vaginal swabs daily so the dynamics of the microbiota could be intensively followed in smoking cessation.

\section{Conclusion}

To our knowledge, this is the first study to assess differences in the vaginal microbiota between smokers and non-smokers and to begin to assess how smoking cessation affects the vaginal microbiome. We found smoking is associated with a vaginal microbiota which has low proportions of Lactobacillus spp, however future research is needed to establish if smoking is causally related to BV and to assess if smoking interventions could positively affect the vaginal microbiome. If smoking cessation proves to reduce incidence, persistence or recurrence of $\mathrm{BV}$, it 
may also offer an additional incentive for women to quit smoking.

\section{Competing interests}

The authors declare that they have no competing interest.

\section{Authors' contributions}

RMB conceived and designed the study, analyzed the data and drafted the manuscript. XH aided in the statistical analysis and conducted the CART analysis. PG and JR developed the bioinformatics pipeline, assigned taxa to the sequencing data and generated figures. DF and JR developed protocols for DNA extraction and bacterial sequencing. JMR, ES, EM, and EG assisted with design and coordination of the study. JMR, EG, ES also provided guidance on design of the smoking cessation protocol and collecting behavioral data on smokers. All authors read and approved the final manuscript.

\section{Authors' information}

Elbert D. Glover and Jessica M. Rath contributed equally as senior authors.

\section{Acknowledgements}

We thank Drs. Jane Schwebke and Charles Rivers (University of Alabama, Birmingham) for performing the Nugent Gram stain scoring. We also thank Barbara Banchero, Research Assistant (CHBR) for implementation of weekly visits, participant recruitment and retention and Melissa Nandy, RN, for assisting with sample inventory and sample coordination.

\section{Funding}

This study was supported by National Institutes of Health grant K01-Al080974 (Brotman) and University of Maryland College Park and University of Maryland Baltimore Seed Grant (Brotman and Glover).

\section{Author details}

${ }^{1}$ Institute for Genome Sciences, University of Maryland School of Medicine, Baltimore, MD, USA. ${ }^{2}$ Department of Epidemiology and Public Health, University of Maryland School of Medicine, 801 West Baltimore Street, Room Number 633, Baltimore, MD 21201, USA. ${ }^{3}$ Department of Epidemiology and Biostatistics, University of Maryland School of Public Health, College Park, MD, USA. ${ }^{4}$ Department of Behavioral and Community Health, University of Maryland School of Public Health, College Park, MD, USA. ${ }^{5}$ Westat, Rockville, MD, USA. ${ }^{6}$ Department of Microbiology and Immunology, University of Maryland School of Medicine, Baltimore, MD, USA. ${ }^{7}$ American Legacy Foundation, Washington, DC, USA.

\section{Received: 10 March 2014 Accepted: 18 August 2014}

Published: 28 August 2014

\section{References}

1. Larsson PG, Platz-Christensen JJ, Sundstrom E: Is bacterial vaginosis a sexually transmitted disease? Int J STD AIDS 1991, 2(5):362-364.

2. Hellberg D, Nilsson S, Mardh PA: Bacterial vaginosis and smoking. Int I STD AIDS 2000, 11(9):603-606

3. Hay PE, Lamont RF, Taylor-Robinson D, Morgan DJ, Ison C, Pearson J: Abnormal bacterial colonisation of the genital tract and subsequent preterm delivery and late miscarriage. BMJ 1994, 308(6924):295-298.

4. Nelson DB, Bellamy S, Odibo A, Nachamkin I, Ness RB, Allen-Taylor L: Vaginal symptoms and bacterial vaginosis (BV): how useful is self-report? Development of a screening tool for predicting BV status. Epidemiol Infect 2007, 135(8):1369-1375.

5. Larsson PG, Fahraeus L, Carlsson B, Jakobsson T, Forsum U: Predisposing factors for bacterial vaginosis, treatment efficacy and pregnancy outcome among term deliveries; results from a preterm delivery study. BMC Womens Health 2007, 7:20.

6. Miller GC, McDermott R, McCulloch B, Fairley CK, Muller R: Predictors of the prevalence of bacterial STI among young disadvantaged Indigenous people in north Queensland. Australia Sex Transm Infect 2003, 79(4):332-335.

7. Cherpes TL, Hillier SL, Meyn LA, Busch JL, Krohn MA: A delicate balance: risk factors for acquisition of bacterial vaginosis include sexual activity, absence of hydrogen peroxide-producing lactobacilli, black race, and positive herpes simplex virus type 2 serology. Sex Transm Dis 2008, 35(1):78-83.

8. Peters N, Van Leeuwen AM, Pieters WJ, Hollema H, Quint WG, Burger MP. Bacterial vaginosis is not important in the etiology of cervical neoplasia: a survey on women with dyskaryotic smears. Sex Transm Dis 1995, 22(5):296-302.

9. Bailey JV, Farquhar C, Owen C: Bacterial vaginosis in lesbians and bisexual women. Sex Transm Dis 2004, 31(11):691-694.

10. Smart S, Singal A, Mindel A: Social and sexual risk factors for bacterial vaginosis. Sex Transm Infect 2004, 80(1):58-62.

11. Thorsen P, Vogel I, Molsted K, Jacobsson B, Arpi M, Møller BR, Jeune B: Risk factors for bacterial vaginosis in pregnancy: a population-based study on Danish women. Acta Obstet Gynecol Scand 2006, 85(8):906-911.

12. Bradshaw CS, Walker SM, Vodstrcil LA, Bilardi JE, Law M, Hocking JS, Fethers KA, Fehler G, Petersen S, Tabrizi SN, Chen MY, Garland SM, Fairley CK: The influence of behaviours and relationships on the vaginal microbiota of women and their female partners: The WOW Health Study. J Infect Dis 2013, 209(10):1562-1572.

13. Bradshaw CS, Morton AN, Garland SM, Morris MB, Moss LM, Fairley CK: Higher-risk behavioral practices associated with bacterial vaginosis compared with vaginal candidiasis. Obstet Gynecol 2005, 106(1):105-114

14. Hillier SL, Holmes KK, Marrazzo JM: Bacterial Vaginosis. In Sex Transm Dis. 4th edition. New York: McGraw-Hill, Health Professions Division; 2008:737-768.

15. Workowski KA, Berman S: Centers for Disease C, Prevention: Sexually transmitted diseases treatment guidelines, 2010. MMWR Recomm Rep 2010, 59(RR-12):1-110.

16. Bilardi JE, Walker S, Temple-Smith M, McNair R, Mooney-Somers J, Bellhouse C, Fairley CK, Chen MY, Bradshaw C: The Burden of Bacterial Vaginosis: Women's Experience of the Physical, Emotional, Sexual and Social Impact of Living with Recurrent Bacterial Vaginosis. PLoS One 2013, 8(9):e74378.

17. Brotman RM, Klebanoff MA, Nansel TR, Yu KF, Andrews WW, Zhang J, Schwebke JR: Bacterial vaginosis assessed by gram stain and diminished colonization resistance to incident gonococcal, chlamydial, and trichomonal genital infection. J Infect Dis 2010, 202(12):1907-1915.

18. Sobel JD, Ferris D, Schwebke J, Nyirjesy P, Wiesenfeld HC, Peipert J, Soper D, Ohmit SE, Hillier SL: Suppressive antibacterial therapy with $0.75 \%$ metronidazole vaginal gel to prevent recurrent bacterial vaginosis. Am J Obstet Gynecol 2006, 194(5):1283-1289.

19. Bradshaw CS, Morton AN, Hocking J, Garland SM, Morris MB, Moss LM, Horvath LB, Kuzevska I, Fairley CK: High recurrence rates of bacterial vaginosis over the course of 12 months after oral metronidazole therapy and factors associated with recurrence. J Infect Dis 2006, 193(11):1478-1486.

20. Bagaitkar J, Demuth DR, Scott DA: Tobacco use increases susceptibility to bacterial infection. Tob Induc Dis 2008, 4:12.

21. Hellberg D, Nilsson S, Haley NJ, Hoffman D, Wynder E: Smoking and cervical intraepithelial neoplasia: nicotine and cotinine in serum and cervical mucus in smokers and nonsmokers. Am J Obstet Gynecol 1988 158(4):910-913.

22. Sasson IM, Haley NJ, Hoffmann D, Wynder EL, Hellberg D, Nilsson S: Cigarette smoking and neoplasia of the uterine cervix: smoke constituents in cervical mucus. N Engl J Med 1985, 312(5):315-316.

23. Schiffman MH, Haley NJ, Felton JS, Andrews AW, Kaslow RA, Lancaster WD, Kurman RJ, Brinton LA, Lannom LB, Hoffmann D: Biochemical epidemiology of cervical neoplasia: measuring cigarette smoke constituents in the cervix. Cancer Res 1987, 47(14):3886-3888.

24. Westhoff C, Gentile G, Lee J, Zacur H, Helbig D: Predictors of ovarian steroid secretion in reproductive-age women. Am J Epidemiol 1996, 144(4):381-388.

25. Hillier SL, Lau RJ: Vaginal microflora in postmenopausal women who have not received estrogen replacement therapy. Clin Infect Dis 1997, 25(Suppl 2):S123-S126.

26. Hummelen R, Macklaim JM, Bisanz JE, Hammond JA, McMillan A, Vongsa R, Koenig D, Gloor GB, Reid G: Vaginal Microbiome and Epithelial Gene Array in Post-Menopausal Women with Moderate to Severe Dryness. PLoS One 2011, 6(11):e26602.

27. Brotman RM, Shardell MD, Gajer P, Fadrosh D, Chang K, Silver MI, Viscidi RP, Burke AE, Ravel J, Gravitt PE: Association between the vaginal microbiota, menopause status, and signs of vulvovaginal atrophy. Menopause 2014, 21(5):450-458.

28. Pavlova SI, Tao L: Induction of vaginal Lactobacillus phages by the cigarette smoke chemical benzo[a]pyrene diol epoxide. Mutat Res 2000, 466(1):57-62. 
29. Nugent $R$, Krohn M, Hillier S: Reliability of diagnosing bacterial vaginosis is improved by a standardized method of Gram stain interpretation. J Clin Microbiol 1991, 29:297-301.

30. Menard JP, Fenollar F, Raoult D, Boubli L, Bretelle F: Self-collected vaginal swabs for the quantitative real-time polymerase chain reaction assay of Atopobium vaginae and Gardnerella vaginalis and the diagnosis of bacterial vaginosis. EurJ Clin Microbiol Infect Dis 2012, 31(4):513-518.

31. Forney LJ, Gajer P, Williams CJ, Schneider GM, Koenig SS, McCulle SL, Karlebach S, Brotman RM, Davis CC, Ault K, Ravel J: Comparison of self-collected and physician-collected vaginal swabs for microbiome analysis. J Clin Microbiol 2010, 48(5):1741-1748.

32. Nelson DB, Bellamy S, Gray TS, Nachamkin I: Self-collected versus providercollected vaginal swabs for the diagnosis of bacterial vaginosis: an assessment of validity and reliability. J Clin Epidemio/ 2003, 56(9):862-866

33. Bai G, Gajer P, Nandy M, Ma B, Yang H, Sakamoto J, Blanchard MH, Ravel J, Brotman RM: Comparison of storage conditions for human vaginal microbiome studies. PLoS One 2012, 7(5):e36934.

34. Fiore MC, Bailey WC, Cohen SJ, Dorfman SF, Goldstein MG, Gritz ER, Heyman RB, Jaén CR, Kottke TE, Lando HA: Treating tobacco use and dependence: clinical practice guideline; 2000.

35. Heffner JL DK, Jansern J, Nolting SL, Winders-Barrett S, Anthenelli RM: Guide to clearing the air (modified). Unpublished treatment manual. In University of Cincinnati; 2007.

36. Henningfield JE, Shiffman S, Ferguson SG, Gritz ER: Tobacco dependence and withdrawal: science base, challenges and opportunities for pharmacotherapy. Pharmacol Ther 2009, 123(1):1-16.

37. Montalto NJ, Wells WO: Validation of self-reported smoking status using saliva cotinine: a rapid semiquantitative dipstick method. Cancer Epidemiol Biomarkers Prev 2007, 16(9):1858-1862.

38. Sandberg A, Sköld CM, Grunewald J, Eklund A, Wheelock ÅM: Assessing recent smoking status by measuring exhaled carbon monoxide levels. PLoS One 2011, 6(12):e28864.

39. Marrone GF, Shakleya DM, Scheidweiler KB, Singleton EG, Huestis MA, Heishman SJ: Relative performance of common biochemical indicators in detecting cigarette smoking. Addiction (Abingdon, England) 2011 106(7):1325-1334.

40. Marrone GF, Paulpillai M, Evans RJ, Singleton EG, Heishman SJ: Breath carbon monoxide and semiquantitative saliva cotinine as biomarkers for smoking. Hum Psychopharmacol Clin Exp 2010, 25(1):80-83.

41. Middleton ET, Morice AH: Breath carbon monoxide as an indication of smoking habit. Chest 2000, 117(3):758-763.

42. Benowitz NL: Cotinine as a biomarker of environmental tobacco smoke exposure. Epidemiol Rev 1996, 18(2):188-204

43. Hurt RD, Dale LC, Offord KP, Lauger GG, Baskin LB, Lawson GM, Jiang NS, Hauri PJ: Serum nicotine and cotinine levels during nicotine-patch therapy. Clin Pharmacol Ther 1993, 54(1):98-106

44. Ravel J, Gajer P, Abdo Z, Schneider GM, Koenig SS, McCulle SL, Karlebach S, Gorle R, Russell J, Tacket CO, Brotman RM, Davis CC, Ault K, Peralta L, Forney $\sqcup$ : Vaginal microbiome of reproductive-age women. Proc Natl Acad Sci U S A 2011, 108(Suppl 1):4680-4687

45. Frank JA, Reich Cl, Sharma S, Weisbaum JS, Wilson BA, Olsen GJ: Critical evaluation of two primers commonly used for amplification of bacterial 16S rRNA genes. Appl Environ Microbiol 2008, 74(8):2461-2470.

46. Ravel J, Brotman RM, Gajer P, Ma B, Nandy M, Fadrosh DW, Sakamoto J, Koenig SS, Fu L, Zhou X, Hickey RJ, Schwebke JR, Forney LJ: Daily temporal dynamics of vaginal microbiota before, during and after episodes of bacterial vaginosis. Microbiome 2013, 1(1):29.

47. Edgar RC: Search and clustering orders of magnitude faster than BLAST. Bioinformatics 2010, 26(19):2460-2461.

48. Edgar RC, Haas BJ, Clemente JC, Quince C, Knight R: UCHIME improves sensitivity and speed of chimera detection. Bioinformatics 2011, 27(16):2194-2200.

49. Wang Q, Garrity GM, Tiedje JM, Cole JR: Naive Bayesian classifier for rapid assignment of rRNA sequences into the new bacterial taxonomy. Appl Environ Microbiol 2007, 73(16):5261-5267.

50. Gajer P, Brotman RM, Bai G, Sakamoto J, Schutte UM, Zhong X, Koenig SS, Fu L, Ma ZS, Zhou X, Abdo Z, Forney LJ, Ravel J: Temporal dynamics of the human vaginal microbiota. Sci Transl Med 2012, 4(132):132ra152.

51. Macklaim JM, Gloor GB, Anukam KC, Cribby S, Reid G: At the crossroads of vaginal health and disease, the genome sequence of Lactobacillus iners AB-1. Proc Natl Acad Sci U S A 2011, 108(Suppl 1):4688-4695.
52. McMillan A, Macklaim JM, Burton JP, Reid G: Adhesion of Lactobacillus iners AB-1 to Human Fibronectin: A Key Mediator for Persistence in the Vagina? Reproduct Sci (Thousand Oaks, Calif) 2013, 20(7):791-796.

53. Verstraelen $H$, Verhelst $R$, Claeys $G$, De BE, Temmerman M, Vaneechoutte M: Longitudinal analysis of the vaginal microflora in pregnancy suggests that L. crispatus promotes the stability of the normal vaginal microflora and that L. gasseri and/or L. iners are more conducive to the occurrence of abnormal vaginal microflora. BMC Microbiol 2009, 9:116.

54. Witkin SS, Mendes-Soares H, Linhares IM, Jayaram A, Ledger WJ, Forney LJ: Influence of vaginal bacteria and D- and L-lactic acid isomers on vaginal extracellular matrix metalloproteinase inducer: implications for protection against upper genital tract infections. mBio 2013, 4(4):e00460-13.

55. Fredricks DN: Molecular methods to describe the spectrum and dynamics of the vaginal microbiota. Anaerobe 2011, 17(4):191-195

56. Mitchell C, Manhart LE, Thomas K, Fiedler T, Fredricks DN, Marrazzo J: Behavioral predictors of colonization with Lactobacillus crispatus or Lactobacillus jensenii after treatment for bacterial vaginosis: a cohort study. Infect Dis Obstet Gynecol 2012, 2012:706540.

57. Ma B, Brotman RM, Gajer P, Fadrosh D, Mahurkar A, White O, Terplan M, Bavoil P, Forney LJ, Ravel J: Association between Chlamydia trachomatis genital infections and the vaginal microbiome. In The International Society for Sexually Transmitted Disease Research, 20th Biennial Congress: July 14-17, 2013 2013. Vienna, Austria: 2013

58. Rigotti NA, Thorndike AN, Regan S, McKool K, Pasternak RC, Chang Y, Swartz S, Torres-Finnerty N, Emmons KM, Singer DE: Bupropion for smokers hospitalized with acute cardiovascular disease. Am J Med 2006, 119(12):1080-1087

59. Hurt RD, Sachs DP, Glover ED, Offord KP, Johnston JA, Dale LC, Khayrallah MA, Schroeder DR, Glover PN, Sullivan CR, Croghan IT, Sullivan PM: A comparison of sustained-release bupropion and placebo for smoking cessation. N Engl J Med 1997, 337(17):1195-1202

60. Eisenberg MJ, Grandi SM, Gervais A, O'Loughlin J, Paradis G, Rinfret S, Sarrafzadegan N, Sharma S, Lauzon C, Yadav R, Pilote L, ZESCA Investigators: Bupropion for smoking cessation in patients hospitalized with acute myocardial infarction: a randomized, placebo-controlled trial. J Am Coll Cardiol 2013, 61(5):524-532

61. DeZee KJ, Wink JS, Cowan CM: Internet Versus In-Person Counseling for Patients Taking Varenicline for Smoking Cessation. Mil Med 2013, 178(4):401-405.

62. Srinivasan S, Liu C, Mitchell CM, Fiedler TL, Thomas KK, Agnew KJ, Marrazzo JM, Fredricks DN: Temporal Variability of Human Vaginal Bacteria and Relationship with Bacterial Vaginosis. PLoS One 2010, 5(4):e10197.

63. Keane FE, Ison CA, Taylor-Robinson D: A longitudinal study of the vaginal flora over a menstrual cycle. Int J STD AIDS 1997, 8(8):489-494.

64. Rubinstein ML, Shiffman S, Rait MA, Benowitz NL: Race, gender, and nicotine metabolism in adolescent smokers. Nicotine Tob Res 2013, 15(7):1311-1315

65. Pérez-Stable EJ, Herrera B, Jacob P, Benowitz NL: Nicotine metabolism and intake in black and white smokers. JAMA 1998, 280(2):152-156.

66. Caraballo RS, Giovino GA, Pechacek TF, Mowery PD, Richter PA, Strauss WJ, Sharp DJ, Eriksen MP, Pirkle JL, Maurer KR: Racial and ethnic differences in serum cotinine levels of cigarette smokers: Third National Health and Nutrition Examination Survey, 1988-1991. JAMA 1998, 280(2):135-139.

67. Vodstrcil LA, Hocking JS, Law M, Walker S, Tabrizi SN, Fairley CK, Bradshaw CS: Hormonal contraception is associated with a reduced risk of bacterial vaginosis: a systematic review and meta-analysis. Plos One 2013, 8(9):e73055.

68. Bulletins-Gynecology ACoP: ACOG practice bulletin. No. 73: Use of hormonal contraception in women with coexisting medical conditions. Obstet Gynecol 2006, 107:1453-1472.

doi:10.1186/1471-2334-14-471

Cite this article as: Brotman et al: Association between cigarette smoking and the vaginal microbiota: a pilot study. BMC Infectious Diseases 2014 14:471. 